\title{
Pengenalan Bahasa Isyarat Tangan Menggunakan Depth Image
}

\author{
Try Yuliandre Pajar, Djoko Purwanto, dan Hendra Kusuma \\ Departemen Teknik Elektro, Fakultas Teknologi Elektro, Institut Teknologi Sepuluh Nopember (ITS) \\ E-mail:try13@mhs.ee.its.ac.id, djoko@ee.its.ac.id, hendraks@ee.its.ac.id
}

\begin{abstract}
Abstrak-Sistem pengenalan bahasa isyarat menggunakan pengolahan visual digital. Pada studi ini sistem mengambil citra gambar menggunakan depth sensor. Depth sensor digunakan untuk mendapatkan gambar tangan sehingga tahap pengambilan kontur berbeda dibandingkan dengan kamera RGB. Depth sensor yang diatur jarak pembacaanya dapat menghasilkan gambar kontur tangan. Menggunakan metode convex hull, convexity defects, dan pusat massa gambar dapat menghasilkan nilai-nilai yang dapat dilatih untuk melakukan pengenalan pada tahap uji cobanya. Sistem ini dapat menangkap citra tangan dari jarak $50 \mathrm{~cm}$ hingga $65 \mathrm{~cm}$. Sistem ini dilatih menggunakan artificial neural network dengan dua kondisi percobaan. Percobaan pertama menggunakan delapan output berdasarkan koordinat yang didapat. Percobaan kedua menggunakan tiga input berdasarkan panjang garis dan luas. Hasil yang dicapai sistem ini yaitu dapat mengenali gestur bahasa isyarat tangan berdasarkan hasil pelatihan. Hasil pelatihan ditentukan dari elemen penyusun neural network dan banyaknya iterasi yang dilakukan, pada ragam huruf yang sedikit akurasi hasil pelatihan dapat memenuhi target output sebaliknya jika ragam huruf bertambah banyak.
\end{abstract}

Kata Kunci-Bahasa Isyarat, Kinect, Machine Vision, Depth Sensor.

\section{PENDAHULUAN}

$\mathrm{K}$ ETERBATASAN dalam berkomunikasi masih menjadi sebuah masalah yang dirasakan oleh orang-orang yang menderita gangguan berbicara seperti tunawicara, tunarungu, dan sejenisnya. Contohnya pada orang yang tidak mampu berbicara seperti tunawicara atau tunarungu menggunakan isyarat tangan. Permasalahannya adalah penggunaan isyarat tangan tidak selalu dimengerti oleh orang normal sehingga dibutuhkan perangkat tambahan yang mampu mengubah isyarat tangan menjadi sebuah keluaran baru yang dapat dipahami oleh orang normal.

Perkembangan teknologi machine vision dapat diterapkan dalam bermacam-macam persoalan, salah satunya pada studi ini. Penggunaan bahasa isyarat tangan dimana citra dari gestur tangan tersebut akan digunakan sebagai acuan dalam pemrosesan machine vision dimana gestur tangan yang dihasilkan akan diolah menjadi suara. Perangkat utama yang digunakan adalah kinect, personal computer (PC), dan speaker. Pengenalan gestur tangan (Hand Gesture Recognition) menggunakan Kinect ini diproses oleh personal computer (PC) dan output yang dihasilkan berupa suara menggunakan speaker. Perangkat Kinect dari Microsoft menyediakan cara untuk mengekstrak fitur diskriminatif untuk pengenalan isyarat tangan. Pendekatan pengakuan dari Kinect terdiri dari dua tahap: tahap pelatihan dan tahap pengenalan [1]. Gestur tangan yang dikenali ini akan merepresentasikan tiap huruf alfabet dan nantinya output audio yang dihasilkan adalah pengejaan huruf tersebut.

\section{DASAR TEORI}

\section{A. Bahasa Isyarat}

Fungsi bahasa pada dasarnya terbagi menjadi tiga elemen yaitu pembicara, pendengar, dan sebuah sistem [2]. Bahasa isyarat merupakan suatu bentuk komunikasi yang menggunakan bahasa tubuh, tangan, dan gerak bibir namun tidak lisan untuk mengekspresikan pikiran penggunanya [3]. Kaum tunarungu dan tunawicara adalah kelompok utama yang menggunakan bahasa isyarat. Bahasa ini merupakan kombinasi dari bentuk tangan orientasi dan gerak jari, tangan, dan lengan.

Bahasa isyarat memiliki sistem berdasarkan region seperti amerika memiliki American Sign Language (ASL). Indonesia memiliki sistem bahasa isyarat Indonesian Sign Language (ISL) atau sistem Isyarat Bahasa Indonesia (SIBI), sistem ini memiliki kesamaan dengan ASL.

\section{B. Kinect}

Kinect adalah perangkat elektronik dengan teknologi software yang dikembangkan oleh Microsoft. Kinect awalnya digunakan sebagai kontroler tambahan pada konsol game Xbox 360. Perangkat Kinect memiliki kamera RGB, Depth Sensor, motorized tilt, dan multi-array microphone [3]. Depth Sensor pada kinect merupakan kombinasi dari laser inframerah dan sensor CMOS monokromatik. Kinect generasi pertama dirilis pada november 2010 kemudian pada februari 2012 generasi kedua dari perangkat ini dirilis. Pada studi ini kinect yang digunakan adalah kinect generasi pertama.Kinect dapat dikembangkan dengan beberapa macam software, salah satunya adalah Microsoft SDK kinect yang diproduksi dari Microsoft sendiri. Selain SDK, kinect juga memiliki berbagai macam library yang dapat digunakan untuk pengembangannya. Pada studi ini library yang digunakan adalah OpenNI.

\section{Kinect}

Kinect adalah perangkat elektronik dengan teknologi software yang dikembangkan oleh Microsoft. Kinect awalnya digunakan sebagai kontroler tambahan pada konsol game Xbox 360. Perangkat Kinect memiliki kamera RGB, Depth 
Sensor, motorized tilt, dan multi-array microphone [3]. Depth Sensor pada kinect merupakan kombinasi dari laser inframerah dan sensor CMOS monokromatik. Kinect generasi pertama dirilis pada november 2010 kemudian pada februari 2012 generasi kedua dari perangkat ini dirilis. Pada studi ini kinect yang digunakan adalah kinect generasi pertama.Kinect dapat dikembangkan dengan beberapa macam software, salah satunya adalah Microsoft SDK kinect yang diproduksi dari Microsoft sendiri. Selain SDK, kinect juga memiliki berbagai macam library yang dapat digunakan untuk pengembangannya. Pada studi ini library yang digunakan adalah OpenNI.

\section{Depth Sensor Kinect}

Depth sensor kinect atau sensor kedalaman kinect terdiri dari dua bagian yaitu pemancar inframerah (IR emitter) dan sensor kedalaman inframerah (IR depth sensor) yang merupakan sensor monokrom CMOS (Complimentary Metal Oxide Semiconductor). Pemancar inframerah berfungsi sebagai proyektor yang memancarkan cahaya inframerah dalam pola "pseudo-random dot"[4]. Dot atau titik ini tidak dapat dilihat oleh mata manusia dan terdapat pada permukan objek yang berbeda-beda berdasarkan arah pemancarnya tetapi, titik ini merupakan informasi penting yang nantinya diolah oleh sensor kedalaman inframerah. Sensor kedalaman inframerah burfungsi sebagai pembaca dari dot yang dihasilkan pemancar, sensor akan mengukur jarak tiap dot sehingga terdapat perbedaan nilai tiap dot akan menghasilkan gambar kedalaman atau depthmap. Depthmap didukung oleh resolusi 640 × 480 piksel, $320 \times 240$ piksel, dan $80 \times 60$ piksel [4]. Teknologi dari sensor depth ini berasal dari PrimeSense. Cara pengolahan data depth bekerja sesuai diagram berikut.

Berdasarkan diagram, chip PrimeSense akan mengirimkan sinyal ke pemancar untuk menyalakan lampu dari inframerah jika ada kamera memulai capturing Selain itu chip juga mengirimkan sinyal lain ke sensor inframerah untuk pengambilan data kedalaman sesuai jangkauan yang terlihat sensor. Kemudian pemancar memancarkan inframerah ke segala objek yang berada didepan kemudian sensor kedalaman membaca data berdasarkan jarak yang terukur antara titik dengan sensor, data ini kemudian diteruskan ke chip PrimeSense. Setelah chip PrimeSense menerima data dari sensor yang kemudian dianalisa sehingga dapat menampakkan gambar kedalaman.

\section{E. OpenNI}

OpenNI adalah perangkat lunak antarmuka untuk algoritma pengolahan data sensor kinect. Fungsi dari OpenNI adalah untuk mendefinisikan tipe data yang akan diolah pada kinect seperti warna, depthmap, dan skeleton. OpenNI juga memiliki library yang dapat digunakan untuk mengakses perangkat kinect.

\section{F. OpenCV}

OpenCV adalah suatu pustaka yang mengimplementasikan algoritma dan sintaks pada pengolahan citra. Dimana pengolahan citra terfokus ada mengekstrak suatu informasi dari gambar. OpenCV menyediakan algoritma yang dapat menemukan lokasi objek dan juga pendeteksian warna.

\section{G. Pengolahan Citra digital}

Pengolahan citra digital adalah suatu proses dengan masukan dan keluaran data yang berupa citra. Proses ini bertujuan untuk memanipulasi dan menganalisa suatu informasi citra dengan perangkat komputer. Data yang diolah

Pengolahan citra digital dapat memperbaiki suatu kualitas gambar dan juga dapat digunakan untuk pengenalan suatu objek. Pada studi ini pengolahan citra digital bertujuan untuk mengekstraks fitur dari gambar yang nantinya akan diolah oleh algoritma ANN.

\section{H. Erode}

Erode atau erosi adalah salah satu dari transformasi morfologi dimana proses morfologi ini mengikis batas atau tepi dari suatu gambar biner. Erode merupakan salah satu dari operator dasar pada morfologi [5], operator ini biasanya bekerja pada gambar biner. Pada gambar biner operator ini akan mengikis tepi gambar akan dibuang bergantung dari ukuran dan bentuk dari kernel. Operator erode bekerja dengan menggunakan dua data yaitu gambar masukan dan structuring element atau kernel

\section{Dilate}

Dilate atau pelebaran adalah satu dari transformasi morfologi dimana proses morfologi ini menebalkan batas atau tepi dari suatu gambar biner. Dilate merupakan salah satu fari operator dasar pada morfologi selain erode, operator ini menebalkan suatu tepi dari gambar biner berdasarkan ukuran dan bentuk dari kernel. Operator dilate bekerja dengan menggunakan dua data yaitu gambar masukan dan structuring element atau kernel.

\section{J. Convex Hull}

Convex hull adalah suatu himpunan yang terdiri dari beberapa titik dimana sebagaian dari titik tersebut akan terhubung membentuk sebuah garis yang melingkupi semua. Convex Hull mampu meng-cover semua himpunan titik dengan jumlah garis yang paling minimal.

\section{K. Convexity Defects}

Convexity defects adalah pengolahan lebih lanjut dari convex hull dimana convexity defects terdiri dari 4 elemen vektor yang merepresentasikan suatu nilai yaitu start index, end index, farthest point index, fix point depth Start index adalah suatu titik terluar yang terhubung dengan end index, kedua titik ini terhubung mengitari kontur objek sesuai convex hull. Farthest point adalah titik yang memiliki nilai terjauh dari kontur terhadap garis hull. farthest point terletak diantara start index dan end inde. Fixed point depth adalah

\section{Neural Network}

Artificial Neural Network (ANN) adalah sebuah paradigma pengolah informasi yang terinspirasi dari cara kerja sistem saraf secara biologi[6]. Neural network merupakan salah satu komponen penting dalam artificial intelligence (AI). Hal ini telah bertahun-tahun dipelajari dengan harapan mencapai seperti kinerja manusia di berbagai bidang [6].

ANN memiliki berbagai macam definisi, seperti menurut Simon Haykin ANN adalah prosesor dalam jumlah besar yang 
terpasang secara pararel dan memiliki unit pemroses yang sederhana, unit pemroses ini menyimpan hasil pembelajaran yang dapat digunakan kembali [7].

\section{PERANCANGAN SISTEM}

Perancangan sistem ini akan dijelaskan sistem secara keseluruhan terutama pada bagian perangkat lunak karena pada studi ini sistem berperan banyak pada bagian perangkat lunak yang akan mengolah informasi visual. Sistem pengenal bahasa isyarat ini terdiri dari empat komponen utama yaitu pengguna alat, kamera kinect, pengolahan citra digital, dan speaker sebagai output.

\section{A. Perancangan Hardware}

Prinsip kerja dari sistem pengenalan bahasa isyarat ini dimulai dari beberapa tahap. Dimulai dari pengambilan gambar gestur bahasa isyarat pengguna. Gestur tangan yang ditangkap akan diolah berdasarkan jarak yang sudah diatur atau di-threshold pada program sehingga akan didapatkan kontur tangan pengguna. Kemudian kontur tangan yang didapat akan diolah tengan convex hull, convexity defects, dan moment untuk didapatkan fitur yang nantinya dapat diolah oleh algoritma artificial neural network sehingga fungsi sistem dapat mengenali gestur dari bahasa isyarat tangan.

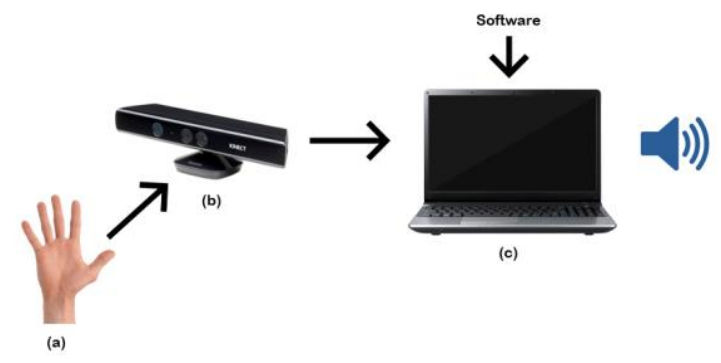

Gambar 1. Ilustrasi cara kerja sistem (a) tangan pengguna; (b) kinect yang terhubung laptop dan suplai ; (c) laptop dan speaker

\section{B. Perancangan Software}

Pada perancangan software atau perangkat lunak sistem akan dirancang untuk mengambil data dan pembelajaran data. Pada proses pengambilan data dilakukan serangkaian proses sebagai berikut:

1. Depth sensor menangkap citra tangan, pada tahap ini sensor depth sudah di atur jarak minimum dan maksimum agar citra tangan lebih mudah didapatkan.

2. Citra tangan yang didapatkan akan diproses menggunakan transformasi morfologi, hasil dari morfologi menghasilkan citra tangan dengan kontur yang lebih halus. Hasil dari proses morfologi akan didapatkan pusat massa dan convex hullnya. Pada convex hull nilai convexity defect didapatkan, nilai-nilai ini terdiri dari start point, end point, farthest point.

3. Hasil dari proses sebelumnya menghasilkan nilai-nilai yang akan dijadikan data set dari gestur tangan. Data set ini digunakan untuk proses pembelajaran pada artificial neural network.

Pada proses pembelajaran atau learning, sistem akan melakukan tahap yang sama pada proses akuisisi data dan pemrosesan video awal. Hasil dari data set yang sudah melalui tahap learning akan digunakan untuk mengenali gestur tangan yang diujikan.

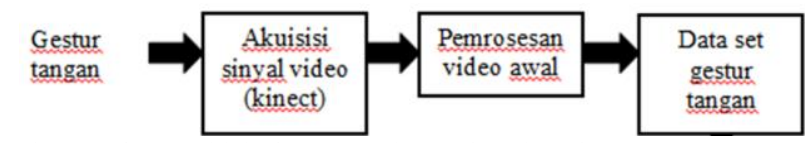

Gambar 2. Diagram blok sistem untuk mendapatkan data set

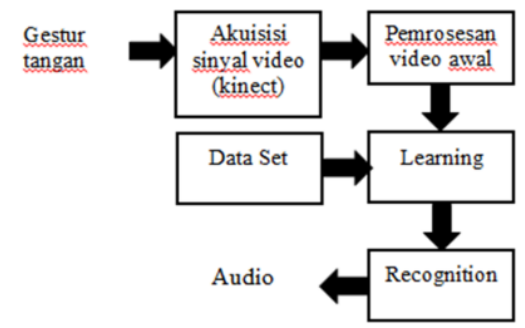

Gambar 3. Diagram blok sistm learning hingga ke output Audio

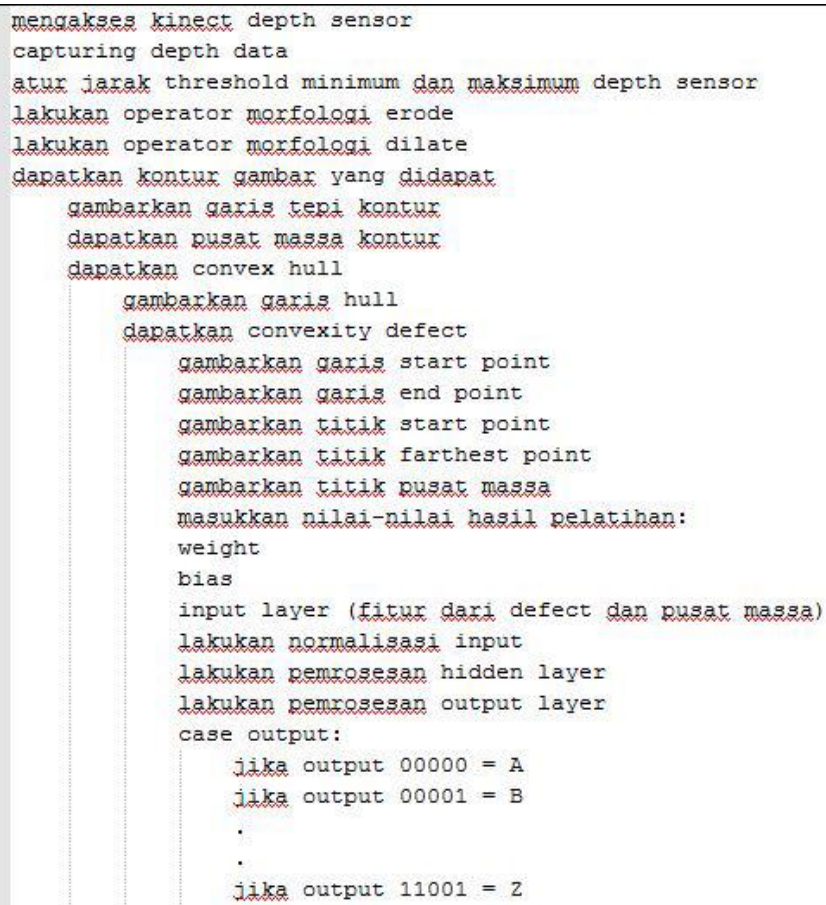

Gambar 4. Algoritma Sistem

\section{Thresholding jarak depth sensor}

Pada pemrograman digunakan library OpenNI untuk mengakses kamera depth kinect. Kemudian dilakukan percobaan untuk mendapatkan jarak yang ideal untuk pengambilan data dan pengujian sistem. Berdasarkan percobaan, jarak minimum yang dipilih adalah $50 \mathrm{~cm}$ dan jarak maksimum adalah $65 \mathrm{~cm}$. Gambar depth yang dihasilkan oleh OpenNI dan dan OpenCV tampak berbeda karen OpenCV hanya mengakses dari segi dua dimensi sedangkan OpenCV sudah terintegrasi oleh perhitungan sensor IR pada kinect sehinggak tampak seperti tiga dimensi. 


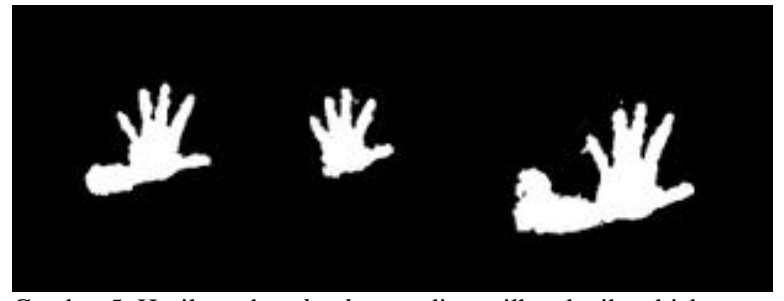

Gambar 5. Hasil gambar depth yang ditampilkan ketika objek memasuki area threshold dengan jarak yang berbeda-beda

Pengujian radius dilakukan untuk mengetahui hasil dari kontur tangan yang didapatkan ketika diberikan threshold jarak pada depth sensor kinect.

Mengikuti urutan gambar tangan (kiri ke kanan). Pada percobaan pertama tangan memasuki area threshold hingga batas siku, pada gambar kedua tangan hingga pergelangan tangan, dan yang ketiga ketika kepala dan bahu juga masuk ke daerah threshold sensor.

\section{Pembentukan Kontur Menggunakan Morfologi}

Hasil gambar tangan yang sudah memasuki area threshold masih akan ditransformasi menggunakan morfologi untuk mendapatkan bentuk yang lebih baik. Pada studi ini dilakukan tiga kali morfologi yaitu erode, closing (erode kemudian dilade), dan dilate. Bentuk kernel yang digunakan adalah rectangular dengan ukuran $3 \times 3$ untuk erode dan $8 \times 8$ untuk dilate.

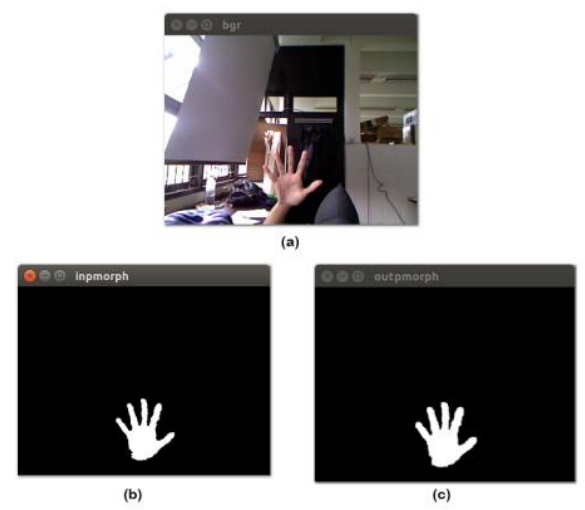

Gambar 6. Proses morfologi (a) gambar BGR; (b) gambar depth yang belum diolah morfologi; (c) gambar depth setelah diolah morfologi

\section{E. Pembentukan Garis Kontur}

Setelah gambar melalui proses morfologi dilakukan proses untuk mendapatkan garis kontur menggunakan fungsi dari OpenCV yaitu findCountours(). Hasil dari findCountours() kemudian diproses lagi untuk menghasilan garis tepi dengan fungsi drawContours().

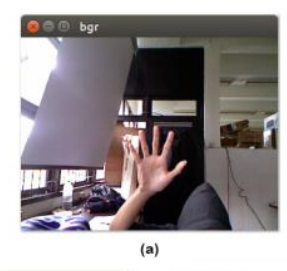

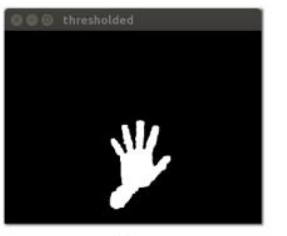

(b) (c)

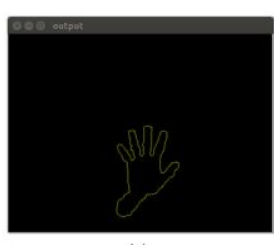

Gambar 7. Draw line contour (a) gambar BGR; (b) gambar depth; (c) hasil penggambaran garis tepi kontur tangan

\section{F. Pembentukan Garis Hull}

Kontur yang didapatkan fungsi findCountours() dapat diolah untuk mendapatkan garis hull dengan fungsi convexHull() dimana fungsi ini menghubungkan titik-titik terjauh yang didapatkan dari output fungsi findCountours(). Kemudian convex yang didapat akan digambarkan oleh fungsi drawContours() sehingga didapatkan garis poligonal yang melingkupi gambar tangan pada tampilan.

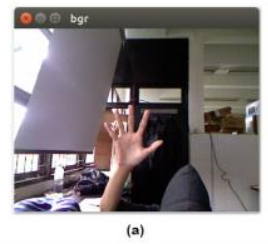

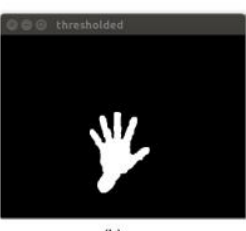

(b)

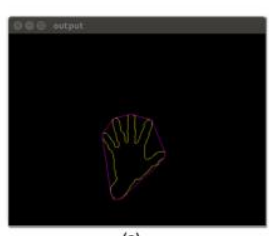

(c)
Gambar 8. Draw convex hull (a) gambar BGR; (b) gambar depth; (c) hasil penggambaran garis hull

\section{G. Pembentukan Defects}

Pembentukan defects didapatkan oleh fungsi convexityDefects() dalam iterasi fungsi convexHull() dimana fungsi ini menghasilkan 4 elemen vektor. Tiga elemen vektor dari fungsi convexityDefects() dapat digambar dan diolah nilainya yaitu start index, end index, farthest point index.

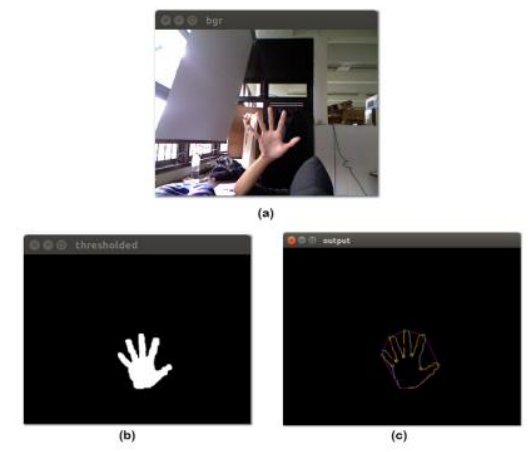

Gambar 9. Draw convexity defects (a) gambar BGR; (b) gambar depth; (c) penambahan titik start point, end point, dan farthest point 


\section{H. Menentukan Pusat Massa}

Pusat massa pada suatu gambar dapat ditemukan menggunakan fungsi moments() dari OpenCV. Moments menggunakan metode rata-rata massa dari intensitas piksel gambar[]. Secara matematis perhitungan pusat

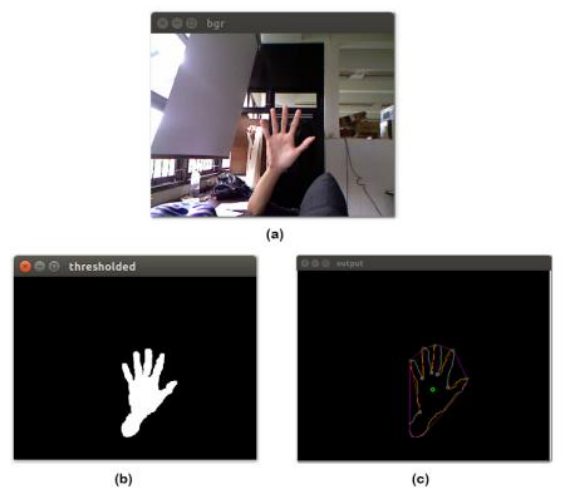

Gambar 10. Draw convexity defects (a) gambar BGR; (b) gambar depth; (c) penambahan titik moments sebagai pusat massa pada kontur tangan

\section{Perancangan ANN}

Fitur-fitur yang didapatkan dari convexity defects dan moments merupakan nilai yang dapat diolah oleh algoritma ANN. Berdasarkan fitur-fitur yang didapatkan akan dirancang kan pengujian ANN berdasarkan jumlah input, hidden layer, dan node. Pengujian berdasarkan jumlah input akan dibagi menjadi 2 yaitu menggunakan 8 input dan 3 input. Pada ANN 8 input, digunakan nilai ptStart.x, ptStart.y, ptEnd.x, ptEnd.y, ptFar.x, ptFar.y, mc.x, dan mc.y. Pada ANN 3 input, digunakan nilai jarak mc-start, mc-far, dan luas dari kontur tangan dengan bentuk rectangular. Input-input ini akan diolah pada ANN dengan output sebanyak 5. Berikut rancangan target dari ANN.

Tabel 1.

Perencanaan target output pada ANN

\begin{tabular}{|c|c|c|c|}
\hline Huruf & Target & Huruf & Target \\
\hline A & 00000 & N & 01101 \\
\hline B & 00001 & O & 01110 \\
\hline C & 00010 & P & 01111 \\
\hline D & 00011 & Q & 10000 \\
\hline E & 00100 & R & 10001 \\
\hline F & 00101 & S & 10010 \\
\hline G & 00110 & T & 10011 \\
\hline H & 00111 & U & 10100 \\
\hline I & 01000 & V & 10101 \\
\hline J & 01001 & W & 10110 \\
\hline K & 01010 & X & 10111 \\
\hline L & 01011 & Y & 11000 \\
\hline M & 01100 & Z & 11001 \\
\hline
\end{tabular}

\section{PENGUJIAN DAN ANALISIS}

\section{A. Kondisi Ideal Pengujian}

Pada studi ini ditentukan kondisi ideal untuk melakukan pengujian yaitu:

1. Hanya ada satu orang di depan kinect.

2. Pengguna hanya bisa mengulurkan tangan ke area pemrosesan kamera.

3. Gambar tangan yang tertangkap berada tepat ditengah.

B. Pengujian ANN

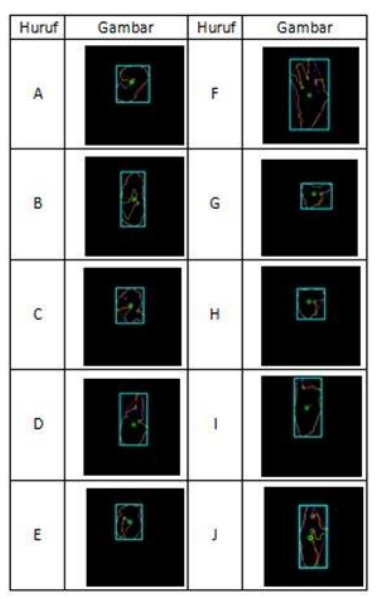

(a)

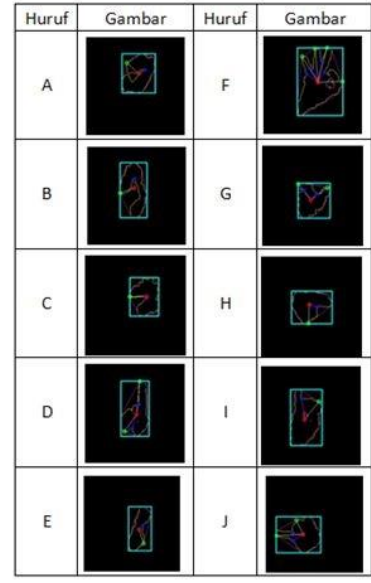

(b)
Gambar 11. (a) Tabel input mulai huruf A sampai J untuk ANN 8 input; (b) Tabel input mulai huruf A sampai J untuk ANN 8 input

Tabel 2 .

Hasil Pengujian ANN 8 Input Untuk 4 Huruf dan 10 Training Set

\begin{tabular}{|l|l|l|l|}
\hline Pengujian & Pertama & Ke-2 & Ke-3 \\
\hline Jumlah Input & 8 & 8 & 8 \\
\hline Jumlah Output & 5 & 5 & 5 \\
\hline Jumlah Huruf & 4 & 4 & 4 \\
\hline $\begin{array}{l}\text { Training Set } \\
\text { Perhuruf }\end{array}$ & 10 & 10 & 10 \\
\hline Banyak Iterasi & 5000 & 5000 & 5000 \\
\hline Jumlah Layer & 2 & 8 & 3 \\
\hline Jumlah Node & $8--2--5$ & $8--8--5$ & $8--4--4--5$ \\
\hline Fungsi Aktivasi & $\begin{array}{l}\text { Log Sigmoid - } \\
\text { Linear }\end{array}$ & $\begin{array}{l}\text { Log Sigmoid - } \\
\text { Linear }\end{array}$ & $\begin{array}{l}\text { Log Sig-Log Sig- } \\
\text { Linear }\end{array}$ \\
\hline Target Sesuai & 40 & 40 & 40 \\
\hline Target Tidak Sesuai & 0 & 0 & 0 \\
\hline Persentase Target & $100 \%$ & $100 \%$ & $100 \%$ \\
\hline
\end{tabular}

Tabel 3.

Hasil Pengujian ANN 8 Input Untuk 4 Huruf dan 40 Training Set

\begin{tabular}{|l|l|l|l|}
\hline Pengujian & Pertama & Ke-2 & Ke-3 \\
\hline Jumlah Input & 8 & 8 & 8 \\
\hline Jumlah Output & 5 & 5 & 5 \\
\hline Jumlah Huruf & 4 & 4 & 4 \\
\hline $\begin{array}{l}\text { Training Set } \\
\text { Perhuruf }\end{array}$ & 40 & 40 & 40 \\
\hline Banyak Iterasi & 5000 & 5000 & 5000 \\
\hline Jumlah Layer & 2 & 2 & 3 \\
\hline Jumlah Node & $8--2--5$ & $8--8--5$ & $8--4--4--5$ \\
\hline Fungsi Aktivasi & Log Sigmoid - & $\begin{array}{l}\text { Log Sigmoid - } \\
\text { Linear }\end{array}$ & $\begin{array}{l}\text { Log Sig-Log Sig- } \\
\text { Linear }\end{array}$ \\
\hline Target Sesuai & 158 & 160 & 160 \\
\hline Target Tidak Sesuai & 2 & 0 & 0 \\
\hline Persentase Target & $98.75 \%$ & $100 \%$ & $100 \%$ \\
\hline
\end{tabular}


Tabel 4.

Hasil Pengujian ANN 8 Input Untuk 16 Huruf

\begin{tabular}{|l|l|l|}
\hline Pengujian & Pertama & Ke-2 \\
\hline Jumlah Input & 8 & 8 \\
\hline Jumlah Output & 5 & 5 \\
\hline Jumlah Huruf & 16 & 16 \\
\hline $\begin{array}{l}\text { Training Set } \\
\text { Perhuruf }\end{array}$ & 40 & 40 \\
\hline Banyak Iterasi & 5000 & 20000 \\
\hline Jumlah Layer & 2 & 2 \\
\hline Jumlah Node & $8--2--5$ & $8--2-5$ \\
\hline & $\begin{array}{l}\text { Log Sigmoid - } \\
\text { Linear }\end{array}$ & $\begin{array}{l}\text { Log Sigmoid - } \\
\text { Linear }\end{array}$ \\
\hline Target Sesuai & 40 & 40 \\
\hline Target Tidak Sesuai & 600 & 600 \\
\hline Persentase Target & $6.25 \%$ & $6.25 \%$ \\
\hline
\end{tabular}

Tabel 5.

Hasil Pengujian ANN 3 Input Untuk 5 Huruf

\begin{tabular}{|l|l|l|l|}
\hline Pengujian & Pertama & Ke-2 & Ke-3 \\
\hline Jumlah Input & 3 & 3 & 3 \\
\hline Jumlah Output & 5 & 5 & 5 \\
\hline Jumlah Huruf & 5 & 5 & 5 \\
\hline $\begin{array}{l}\text { Training Set } \\
\text { Perhuruf }\end{array}$ & 10 & 10 & 10 \\
\hline Banyak Iterasi & 5000 & 5000 & 5000 \\
\hline Jumlah Layer & 2 & 2 & 3 \\
\hline Jumlah Node & $3--2--5$ & $3--8--5$ & $3--4--4--5$ \\
\hline Fungsi Aktivasi & $\begin{array}{l}\text { Log Sigmoid - } \\
\text { Linear }\end{array}$ & $\begin{array}{l}\text { Log Sigmoid - } \\
\text { Linear }\end{array}$ & $\begin{array}{l}\text { Log Sig-Log Sig- } \\
\text { Linear }\end{array}$ \\
\hline Target Sesuai & 26 & 47 & 50 \\
\hline Target Tidak Sesuai & 24 & 3 & 0 \\
\hline Persentase Target & $52 \%$ & $94 \%$ & $100 \%$ \\
\hline & & &
\end{tabular}

Tabel 6.

Hasil Pengujian ANN 3 Input Untuk 10 Huruf

\begin{tabular}{|l|l|l|l|}
\hline Pengujian & Pertama & Ke-2 & Ke-3 \\
\hline Jumlah Input & 3 & 3 & 3 \\
\hline Jumlah Output & 5 & 5 & 5 \\
\hline Jumlah Huruf & 10 & 10 & 10 \\
\hline $\begin{array}{l}\text { Training Set } \\
\text { Perhuruf }\end{array}$ & 10 & 10 & 10 \\
\hline Banyak Iterasi & 5000 & 5000 & 5000 \\
\hline Jumlah Layer & 2 & 2 & 3 \\
\hline Jumlah Node & $3--2--5$ & $3--8--5$ & $3--4--4--5$ \\
\hline & Log Sigmoid - & Log Sigmoid - & $\begin{array}{l}\text { Log Sig-Log Sig- } \\
\text { Linear }\end{array}$ \\
\hline Fungsi Aktivasi & Linear & 10 & 20 \\
\hline Target Sesuai & 10 & 90 & 80 \\
\hline Target Tidak Sesuai & 90 & $10 \%$ & $20 \%$ \\
\hline Persentase Target & $10 \%$ & & \\
\hline
\end{tabular}

\section{Pembahasan Pengujian}

Pada pengujian ANN 8 input, input yang digunakan yaitu ptStart.x, ptStart.y, ptEnd.x, ptEnd.y, ptFar.x, ptFar.y, mc.x, dan mc.y. Nilai ptStart, ptEnd, dan ptFar diperoleh dari convexity defects sedangkan mc diperoleh dari perhitungan pusat massa gambar menggunakan moments. Masing-masing huruf memiliki karakteristik nilai yang berbeda sehingga huruf-huruf ini dilatih menggunakan ANN dengan jumlah training set yang beragam perhurufnya.

Pada pengujian ANN 3 input, input yang digunakan yaitu jarak titik ptStart ke mass center, jarak titik ptFar ke mass center, dan luas dari kotak yang melingkupi kontur. Pada pengujian sebelumnya data yang diolah berupa koordinatkoordinat dari gambar tangan yang didapat sedangkan pada pengujian ini data yang diolah adalah garis sehingga memiliki kondisi yang berbeda saat pengambilan datanya.

\section{KESIMPULAN}

Pada pengujian ini diujikan suatu sistem yang dapat mengenali gestur tangan menggunakan kamera kinect. Penggunaan depth sensor dari kinect dapt dimanfaatkan untuk mendapatkan kontur tangan. Pengambilan kontur tangan membutuhkan metode lagi agar dapat dijadikan data tertentu sehingga data tersebut dapat dilatih dengan artificial neural network. Data yang dilatih ini yang menentukan tingkat keberhasilan dari sistem ini. Berdasarkan pengujian perocobaan dengan jumlah input yang lebih banyak menghasilkan hasil yang lebih akurat dengan jumlah huruf yang hampir sama. Hasil yang dicapai sistem ini masih belum akurat karena proses pelatihan membutuhkan parameterparameter yang lebih kompleks agar proses pengenalan dapat memberikan hasil yang lebih baik.

\section{DAFTAR PUSTAKA}

[1] F. Liu, "Hand Gesture Recognition Using Kinect via Deterministic Learning," Longyan Univ., 2017.

[2] M. Y. Andrian, "Penerjemah Isyarat Indonesia Menggunakan Kamera Telepon Genggam Android," Inst. Teknol. Sepuluh Nop., 2016.

[3] A. A. S. Gunawan, "Pembelajaran Bahasa Isyarat Dengan Kinect dan Metode Tim Warping,” Univ. Binus, 2013.

[4] J. A, "Kinect for Windows SDK Programming Guide," pp. 8-11, 2012.

[5] G. and A. K. Bradsk, "Learning OpenCV: Computer Vision with the OpenCVLibrary," O'Reilly Media, p. 2008, 115AD.

[6] S. Haykin, Neural Networks: A Comprehensive Foundation, 2nd ed. Ontario: Prentice Hall PTR, 1998. 